\title{
Design and Finite Element Analysis of Modular Rubber-Track System Frame
}

\author{
Xiaodong Zhao ${ }^{1}$, Xihui $\mathrm{Mu}^{1}$, Fengpo $\mathrm{Du}^{1}$, Haoliang $\mathrm{Guo}^{1}$, Jianhua Chen ${ }^{1}$ \\ 1Shi jia zhuang new technology application insitute,Shijiazhuang 050000 P.R.China
}

\section{Keywords: Rubber track system, Modular, Finite element analysis}

\begin{abstract}
Without modification or a small wheeled vehicles converted premise modular rubber track system can be a direct replacement tire wheeled vehicles, so that it becomes tracked vehicles, thus increasing its off-road performance.Frame as a key component of the modular rubber track system, supporting all other structures of rubber track system.According to the frame form and its assembly mode of the vehicle,the modular rubber track system can be divided into two kinds of integral type and separated type.The frame of a integral rubber track system design, and its finite element analysis to verify the uniform stress and concentrated stress is less than the uniform allowable stress and concentrated allowable stress.
\end{abstract}

\section{Introduction}

Modular rubber track system is a new application of technology rubber track. It can directly replace the tires of the wheeled vehicle without modification or a small amount of modified wheel vehicle, so as to reduce the ground pressure of the vehicle, improve its traction and power, and improve the off-road performance.The technology is more mature in Europe, North America, widely used in areas such as engineering, military and agriculture. Where representatives of the company are the United States Mattracks, Canada Soucy, Japan's Bridgestone and other companies. In the country is still in the introductory phase, there is a wide gap compared with foreign countries, but the emphasis is increasingly strengthened[1].

The modular rubber track system is composed of many components, including the rubber track, the driving wheel, the frame, the load bearing wheel and the steering wheel system. Wherein the frame as a modular rubber track wheel support member, determines the shape track wheels and determine the layout of other components[2]. The modular rubber track system can be divided into drive type and driven type, in which the driving wheel can be directly replaced by driving wheel, and the driven wheel can change the driven wheel directly.

\section{Classification of modular rubber track wheel frame}

According to the frame form of the triangle track system and the assembly mode of the vehicle , the modular triangle track wheel can be divided into the integral type and the separation type.

\subsection{The integral type}

The triangular track system assembly as a whole, and then the end of the drive shaft to the vehicle drive wheel assembly, the drive wheel rotates with the drive shaft.. Integral triangle track wheels to replace the simple, high degree of modularity.[3] Connection between the drive wheels and the load bearing frame. When driving on uneven ground, the road wheel with the surface lines and frame can swing around the drive shaft and downs together. But bearing connection between the drive wheels and the frame not only carries the vehicle load, but also bear axial force when cornering, harsh working conditions.

\subsection{The separation type}

Driving wheel of the vehicle to the end of the drive shaft assembly, and with the drive shaft. The frame is secured on the drive shaft support housing. There is no direct relationship between the wheels and the frame assembly. Road wheel rotatably mounted on the frame-based, so that it can swing relative to the frame. Road wheel system typically swing pivot at just below the drive shaft, and 
drive shaft are not coaxial. So the swing changes tracked perimeter ring gear train, thus limiting the scope of the swing, is not conducive to driving on rough roads. Additionally, when you install a triangular track wheels need to ensure the load axis of the wheel and the guide wheel parallel to the axis of the drive wheels, in order to ensure the train wheels and track pairs, to avoid tension caused by uneven sides crawler tracked lateral sway.

\section{Design of modular rubber track wheel frame}

Triangle track wheel frame is used to maintain the triangle shape, as shown in Fig. 1Typically, the triangle track wheels should be preferred high degree of modularity in the overall structure. After the modified vehicles, triangular track wheels should move within its replacement tires available space envelope. Under the same conditions of topography, the lower the road wheel system hinged position, weight train wheel swing, the more stable the triangle track wheels, and easy on the adjacent vehicle components interfere. Since the installation space of a truck triangular track wheels is extremely limited, but also to carry large loads, easy replacement of the tire, so the use of monolithic.

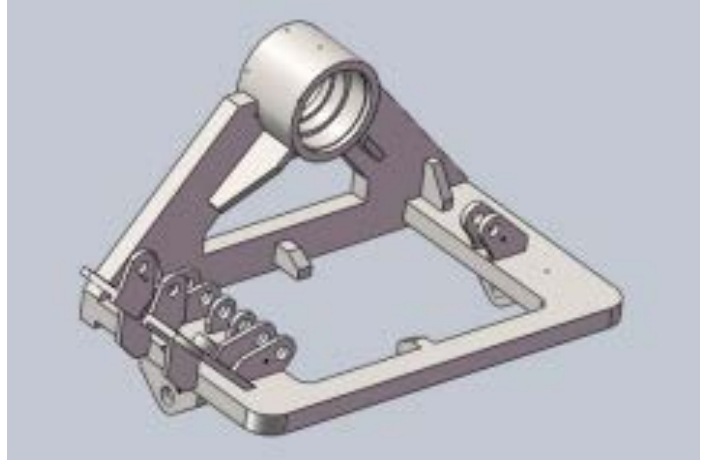

Fig. 1 Three-dimensional model of track assembly

Because of the compact structure of the triangle track wheel, it can not be used in the box structure, but it can be used to improve the steel degree, reduce the deformation of the welded joints, and the frame material is widely used in HJ58C, and the processing technology is mature and the quality is easy to control.

The frame adopts the symmetrical structure, which is favorable for the processing and manufacturing, and the tension cylinder is equipped with the hinged hole and the independent flexible swing arm suspension. The elastic hinge hole in the swing arm suspension on both sides, is conducive to the swing arm suspension hinged shaft bearing deflection torque, the torque in the load when the train track guide.

\section{Finite element analysis of modular rubber track wheel frame}

\section{1 calculation conditions}

The track wheel is mounted on a certain type of forklift, the load driving condition, the full contracting level of the arm, and the quality of $1000 \mathrm{~kg}$. Remove middle load wheel set

load coefficient:dynamic load coefficient1.75,load uneven coefficient1

Frame stress diagram as shown in Figure 2

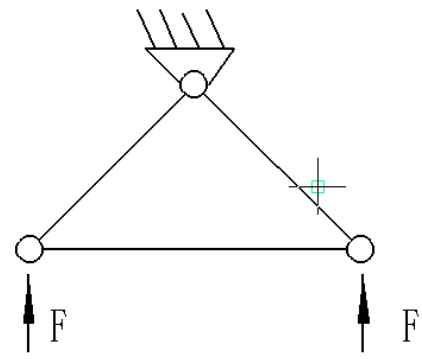

Fig.2 Load driving track wheel frame force diagram

$F_{1}=\left(R_{1} / 4\right) \times 1.75=2767 \mathrm{~kg}$. 


\subsection{Finite element analysis}

Workbench SolidWorks in the finite element analysis software ANSYS, the load and displacement constraints on the model are applied to the finite element analysis software. On the hinge hole $U X=0, U Y=0, U Z=0$ displacement constraint, the corresponding load applied in a train load balance frame hinge point. Grid division is divided into the entity element by free grid.The stress distribution of the ANSYS finite element analysis of the track wheel frame is shown in fig.3.

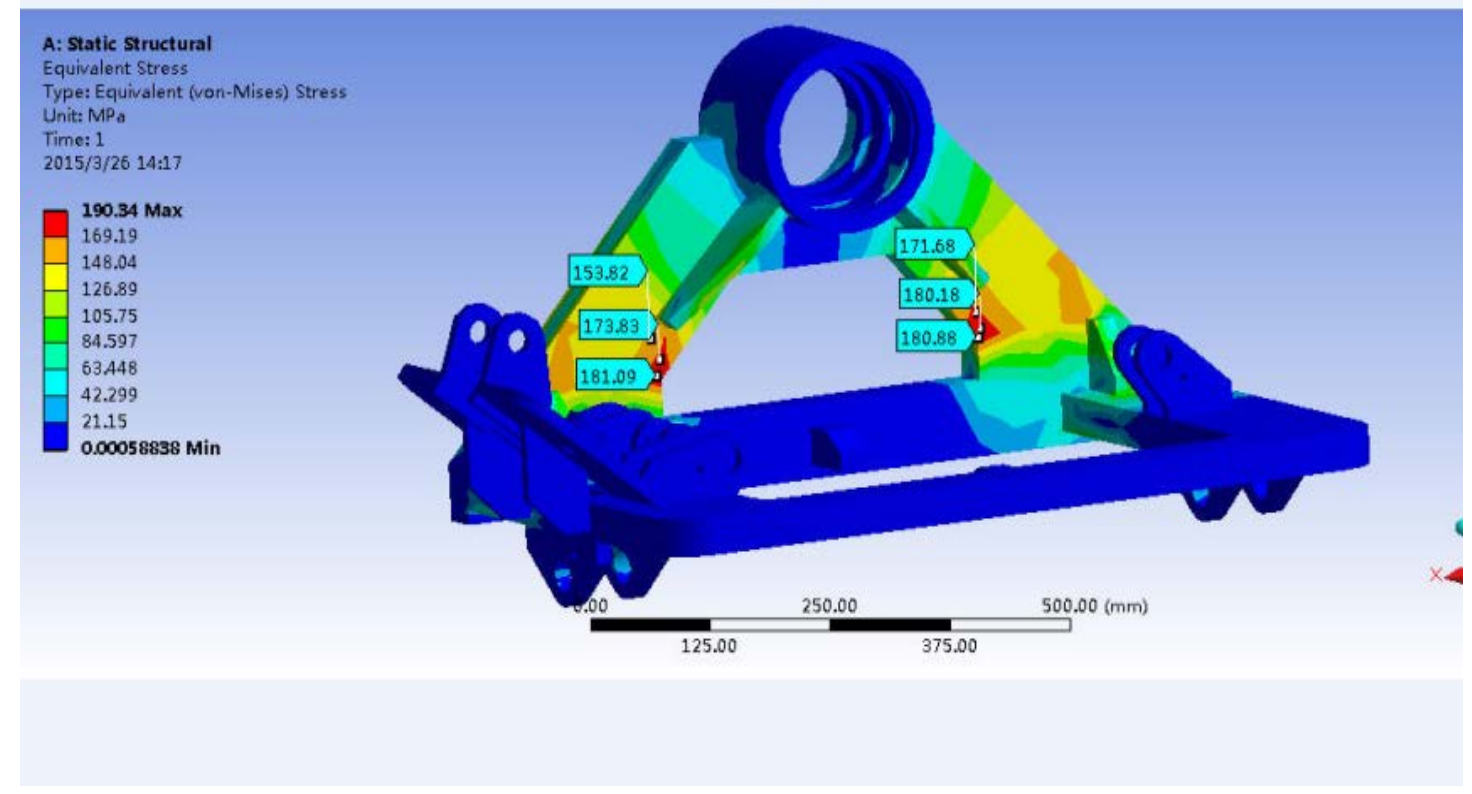

\subsection{Finite element analysis results}

Fig.3 Main support stress distribution

ANSYS finite element analysis and calculation of the most dangerous working conditions of the crawler wheel frame are carried out. The stress results of the finite element analysis of the frame of the crawler wheel are shown in Table 1.

Table 1 Analysis results of frame stress of track wheel

\begin{tabular}{ccc}
\hline Uniform stress (MP) & Concentrated stress (MP) & Maximum concentrated stress (MP) \\
\hline$\sigma \leq 100$ & $\sigma \leq 169$ & $\sigma_{\max }=190$
\end{tabular}

The uniform stress and the stress concentration of the crawler wheel frame in each working condition are smaller than that of the corresponding parts of each part.

\section{Reference}

[1]. Brown H J,Cruse R.M,Erbach D.C,et al. Tractive device effects on soil physical properties.Soil and Tillage Research.VOL.22(1992) NO 1 p 41-53

[2]. Watanabe K,Kitano M,Takano K,et al.Study on rolling resistance of rubber track.Transactions of the Japan Society of Mechanical Engineers.VOL.62(1996) NO603 p 4212-4217I

[3]. Sheridan G J.A comparison of rubber-tyred and steel-tracked skidders on forest soil physical properties.Australian Journal of Soil Research.VOL41(2003) NO6 p 1063-1075 